\title{
"Pasien Pandai" Program: An Effort to Increase Adherence to Medication in Diabetes Mellitus Type 2 Patients
}

\author{
Siti Muthia Dinni \\ Faculty of Psychology, Universitas Ahmad Dahlan, \\ s.m.dinni@gmail.com
}

\begin{abstract}
Diabetes Mellitus type 2 (DM 2) is a type of chronic disease that is essentially incurable. The only possible effort for health maintenance is self-management to keep blood glucose levels normal. Although adherence to medication arrangements is important for patients, their tendency to comply is relatively low. Having seen this problem, there is a need for a psychological intervention that is focused on the growth of acceptance, strengthens commitment for a change, and facilitates behavioral change. The "Pasien PANDAI" (Patients with Acceptance and Action) Program was designed integratively to accommodate the stated three focuses. A QuasiExperiment with The One-Group Pretest-Posttest Design was defined as the study design. The subjects of the experiment were five members Persadia (Diabetes Association of Indonesia), Yogyakarta branch. Data Analysis was done with Wilcoxon Signed Rank Test and descriptive analysis. Research results indicate that "Pasien PANDAI" Program cannot increase adherence to medication in DM 2 patients $(Z=-1,826 ; p>0,05)$ with constant results up until follow-up $(Z=$ $-0,535 ; \mathrm{p}>0,05)$. However, descriptive analysis shows that DM 2 still feels certain benefits from the program.
\end{abstract}

Keywords: Program pasien pandai, acceptance, commitment, action, diabetes mellitus, chronic disease, adherence to treatment.

\section{Introduction}

Diabetes Mellitus (DM) is a chronic disease that is categorized as one of the world's extraordinary medical cases (WHO, 2012). Based WHO facts, in 2012, 347 million people of the worldwide population suffer from diabetes, with more than $80 \%$ of the patients residing in developing countries. The WHO predicts that by 2030 , diabetes will be included in the seven major causes of death in the world (WHO, 2013). The 2013 RISKESDAS Data also showed that the prevalence of diabetes mellitus in Indonesia is high reaching a scale of 2.1. The Province with the highest diabetes prevalence rates in Indonesia is Yogyakarta Special Region (Kemenkes RI, 2013). If this condition is not given sufficient attention, it will threaten the society's health level and can potentially burden the country's financials with longterm care (Dinkes DIY, 2013).

In handling their health care, patients with DM 2 requires strict self-management to keep the blood sugar under control, ensure 
Journal of Educational, Health and Community Psychology

the symptoms are not getting worse, and avoid complications. This process is done not only one but regularly, constantly and permanently throughout the patient's life (Taylor, 2006). Although DM 2 patient's self-management is crucial for one's health, the field condition reveals that many DM 2 patients are having trouble managing their illness and have a low tendency in adhering to their medication arrangements (Hasanat, 2008; Haynes, McDonald, \& Garg, 2002).

A few studies reveal that psychological problems that often emerge in DM 2 patients and hinder their adherence to medication are symptoms of depression and anxiety (Bautista, Vera-Cala, Colombo, \& Smith, 2012). The worse the symptoms of depression and anxiety, the lower the adherence to medication, and vice versa (Bautista, Vera-Cala, Colombo, \& Smith, 2012; Ciechanowski, Katon, \& Russo, 2002; Delamater, 2006; Gray, Denson, Baldassano, \& Hommel, 2011). Symptoms of depression and anxiety often emerge in DM 2 patients due to rejection regarding their condition that is no longer the same. This shows patient's low self-acceptance. Nash (2013) explains this based on Kubler-Ross's grief process. When a person faces traumatic condition or loses something valuable, such as health, the early stages they will face is denial. This denial elicits distress due to drained energy to reject various experiences that relate to diabetes (private experience).
Also, denial will also hinder a person to experience various diabetes-related things and consequently makes the person conducts that conflict with the DM 2 management (Gregg, 2004). Among the forms of denial are rejecting doctor diagnosis, rejecting treatment, and rejection to life-style change. If not handled sufficiently, these denials will cause sickness behavior of DM 2 patients. This condition is marked by loss of vigor and hope, followed by the emergence of a sense of helplessness resulting in physical inactivity in the patient. This consequently causes patients to feel unconfident in selfmanaging their illness (Ridder, Geenen, Kujer, \& Middendorp, 2008).

In addition, denial will also hinder a person to experience various diabetes-related things and consequently makes the person conducts that conflict with the DM 2 management (Gregg, 2004). Among the forms of denial are rejecting doctor diagnosis, rejecting treatment, and rejection to life-style change. If not handled sufficiently, these denials will cause sickness behavior DM, 2 patients. This condition is marked by loss of vigor and hope, followed by the emergence of a sense of helplessness resulting in physical inactivity in the patient. This consequently causes patients to feel unconfident in selfmanaging their illness (Ridder, Geenen, Kujer, \& Middendorp, 2008).

To increase adherence to medication in DM 2 patients, there is a need for a certain 
Journal of Educational, Health and Community Psychology

treatment that is focused on aspects of selfacceptance growth, commitment formation, as well as facilitates real behavioral change. Research prove that intervention based on the three aspects were effective in treating psychological problems in DM 2 patients (Forman, Butryn, Hoffman, \& Herbert, 2009; Gregg, 2004; Hartmann, et al., 2009).

Acceptance involves a willingness to experience inner sensation (thoughts, feelings, and psychological sensation) in a way that is attentive, non-evaluative, and without any attempt to alter or avoid (McCracken \& Vowles, 2006). This implies that acceptance makes one face things in life more lightly and without effort to avoid. Based on Macinness (2006), acceptance is associated with low depression and anxiety hence ensuring a healthier psychological condition.

In addition, acceptance will cause one to make behavioral choices that adhere to their personal values and goals, despite the indecent condition (Hayes, 2004; McCracken \& Vowels 2006). This is achievable because patients with selfacceptance can direct themselves to positive thoughts in viewing their life problems (Hjelle \& Zeigler, 1992 ; Seligman 1991). This explanation confirms that the acceptance is the gate to an emergence of commitment and behavioral change for patients with DM 2.

When the commitment for a behavior change emerges, patients will have a passion to change because they feel a sense of direction (Hayes, 2004). Commitment is a supporting factor to patient's recovery because the patient has the determination and is a willingness to change behaviors despite encountering an assortment of obstacles (Razali, Bee, \& Gan, 2013).

"Pasien PANDAI" Program (Pasien dengan Penerimaan dan Aksi) is an integrative program designed to fulfill the needs of an intervention of chronic disease patients. This program is done in five sessions in the course of two-three weeks. Each session is approximately 120 minutes. The first session of "Pasien PANDAI" Program is an opening, introduction, and a preface to the program. The second session is filled with sharing of experience about their illness, as well as relaxation practice. The third session consists of self-understanding and process of acceptance with mindfulness techniques. The fourth session contains the process of finding a purpose in life, determining the next steps, and commitment to implementation. Finally, the fifth session contains evaluation to the process of implementation of behavioral change, the process of experience-sharing, and also the process of strengthening.

In its execution, this "Pasien PANDAI" Program will use the brief therapy concept (Werch, et al., 2006). According to Chakrabarti (2011), brief therapy is the right form of intervention to be implemented in 
Journal of Educational, Health and Community Psychology

Indonesia considering its effectiveness in costs, efficiency and easiness to of wordspreading. Research shows that although long-term interventions are better in improving the quality of assistance, brief therapy has also proven to create a positive effect and maintain a significant effect on health interventions (Devaramane, Pai, \& Vella, 2011).

Brief therapy that is implemented in the "Pasien PANDAI" Program is done in the form of groups or group brief therapy. This is aimed to support the process of therapeutic change in a group known as therapeutic factors (Yalom \& Leszcz, 2005). Also, the process of intervention in a group can create social support that increases acceptance as well as decrease the level of difficulty in self-management behavior (Misra \& Lager, 2008). This means that interventions in group form are the right thing considering that social support for DM 2 patients can be obtained through the process of interaction, socialization, and the formation of therapeutic relationships in a group.

Past studies proved that interventions based on aspects of acceptance, commitment formation, and also behavioral changes proved to be effective cope with psychological problems in patients with DM 2. Among other research conducted by Gregg (2004) showed that psychoeducation in a group of patients with DM 2 that used
Acceptance and Commitment Therapy (ACT) proved to be effective in improving self-management. They also had lower blood sugar compared with psychoeducation group without ACT. This study consisted of one meeting for 7 hours and involved 81 patients with DM 2 study design randomized controlled trial.

In addition, a joint program between behavior therapy and acceptance-based therapy designed by Forman, Butryn, Hoffman, \& Herbert (2009) proved to be effective for weight loss process in person suffering from obesity. The program focused on increasing participants' commitment to behavior change, build skills to tolerate distress, and encourage the emergence of mindful on eating behavior. This study used a single case design involved 19 participants.

Research of Hartmann, et al. (2009) applies MBSR (Mindfulness Based Stress Reduction) to reduced psychosocial distress in patients with DM 2. MBSR lasted eight weeks which contain physical exercise and meditation to improve transparency, awareness, and acceptance of the internal and external experiences that can help controlling the reaction time to face life stressors and to behave more reflective. The subjects were 110 people, divided into a control group and an experimental group. This study design was a randomized controlled trial. The results of this study indicated that MBSR was an effective intervention for patients 
Journal of Educational, Health and Community Psychology

with DM 2 in lowering psychosocial distress. It was characterized by lower levels of depression and a higher level of health status. Various studies have been presented shows that aspects of reception, following the commitment, and behavioral changes in an intervention shown to overcome the psychological problems in patients with DM 2 so that the management itself can be increased. It also implies that medication adherence increases.

On "Pasien PANDAI" Program, this program adopts the concept OF Acceptance and Commitment Therapy (ACT). It combines acceptance and commitment forming process, then behavioral change process related self-management behavior of patients in facing DM 2. However, the implementation phase and procedures have been adapted to the needs of intervention for patients with chronic diseases, the health condition of patients who tend to fluctuate, and the characteristics of the subjects who are an elderly group. In addition, this program was also carried out in groups and in a brief process unlike ACT procedures in general.

Based on the above evaluation, the aim of this research is to study whether the "Pasien PANDAI" Program can increase adherence to medication in DM 2 patients. The hypothesis of this research is "Pasien PANDAI" Program (Patients with
Acceptance and Action) can increase adherence to medication in DM 2 patients.

\section{Method}

\section{Participants}

Subjects of this study are five DM 2 patients who are members of Persadia (Diabetes Association of Indonesia), Yogyakarta branch. Subjects had a level of adherence to treatment in the low to moderate category, physically able to mobilize independently, can speak Indonesian both orally and in writing, not currently receiving other psychological therapies, willing to participate in the research process, and have contacts that can be contacted.

\section{Instruments}

This study employed seven instruments:

Sheets of Research Information and Participant Approval. This instrument explains to each subject about the procedures of the research, rights and obligation of the subject and researcher, confidentiality of data, and subject's approval to participate without any force from any person (Inform consent).

Adherence to Medication Scale (Cronbach alpha $=.892)$. This Scale is the result of a modification towards the Adherence to Medication Scale (Basyiroh, 2011). This scale consists of 17 items that are used to measure adherence to medication. Some examples of the item of this scale are "I feel 
Journal of Educational, Health and Community Psychology

responsible for running the rule of treatment as agreed with the doctor." "I am looking for a variety of information to increase my knowledge about diabetes." "In a party, I can refrain myself from eating foods or drinks contained high sugar. "

Acceptance and Action Scale (Cronbach alpha $=.831$ ). This scale is a modification of Acceptance And Action Questionnaire (AAQ) (Bond et al., 2011). This scale consists of 15 items that are used to measure emotional acceptance or denial towards chronic illness regarding their coping response. Some examples of the item of this scale are "I often asked God why should I had this disease." "Wherever possible I tried to avoid other people's questions about diabetes.", "I am too scared to think about the impact of diabetes on me."

\section{"Pasien PANDAI" Program Module. The} module provides a basis for thinking about this module, workflow changes that expected, and the intervention implementation guidelines for the facilitator. The Aiken V Score for each session in this program ranged from 0.75 to 0.9375 . That suggests that each session in the "Pasien PANDAI" Program could target the expected goals.

Subject's Diary. This Diary is a book that is compulsory to be filled every day by the subject during the intervention process. This book contains the program schedule, assignment index, relaxation instructions/guide, serenity prayer, a sheet of my today, behavioral checklist, and worksheets when there is homework.

PANDAI Book. PANDAI Book is a book that contains the phases of the program, psychoeducation material for subjects, and also program evaluation sheets and manipulation check.

Observation Sheet. This observation consists of three parts, which are observations the general process of intervention, individual observation sheet of participants, observation sheet implementation of the intervention by the researcher.

\section{Experiment Planning}

This research used "The One-Group PretestPosttest Design" (Shadish, Cook, \& Campbell, 2002). In this research, the researcher added a follow-up process that was done one-week post-intervention.

\section{Intervention}

The goal of the "Pasien PANDAI" Program is for patients with DM 2 to be more accepting towards their condition, gain inner peace, can set goals in the face of illness, make a commitment to make more positive changes, and implement these commitments through a process of behavioral change. It is expected that through this process, the patient's adherence to medication can be improved. The program consists of four 
Journal of Educational, Health and Community Psychology

Vol 5, No 2, 2016

Siti Muthia Dinni

sessions for 2-3 weeks. Each meeting lasts

execution of the program, observation is approximately 2 hours.

done by observing behavior each subject in their groups, group dynamics, facilitator

Every meeting in Program "Pasien

PANDAI" was led by one facilitator. In the condition, and program execution by the facilitator.

Table 1

Patient PANDAI Program Blue Print

\begin{tabular}{ll}
\hline \multicolumn{1}{c}{ Session } & \multicolumn{1}{c}{ Aims } \\
\hline Opening & Facilitating the process of building \\
(120 minutes) & rapport and submitting an \\
& explanation of program \\
& implementation procedures
\end{tabular}

Core activities

Explanation of research, program

objectives, and the involvement of

participants

Introduction and sharing patient

expectations in the following

program

Signing the informed consent form

Filling the diaries by participants

Session I

Sharing and relaxation exercises

(120 minutes)

\section{Session III}

Finding the purpose of life and

making commitment (120 minutes)
Facilitate the emergence of openness and mutual support within the group Familiarize relaxation process

Helping the subject of recognizing the values and purposes of his life, as well as develop a plan for behavior changes Facilitating the emergence of commitment to behavior change
Sharing experience of dealing illness Relaxation exercises

Giving homework assignment

- Relaxation

- Finding purpose in life / value of living with a reflective activity, choose three most important and how you want to be remembered

- Evaluating the effort that has been done so far, mainly related to the treatment

- Developing action plan that is consistent with the objectives (SMART)

- Finding out things that would make patient survives with his commitment to making behavioral changes

- Writing an unsent letter. It will be opened next session. 
Journal of Educational, Health and Community Psychology

Vol 5, No 2, 2016

Siti Muthia Dinni

Session IV

Action

(120 minutes)
- Facilitating the emergence of a real behavior change in the patient by the commitments that have been made
- Explaining the implementation of the "take action" to be performed outside the meeting for one week

- The "take action" implementation process which will be held outside the meeting (1 week)

- Sharing experiences in the running "take action" (Discussing the difficulties and strategies for resolving difficulties)

- Opening the unsent letter and sharing feelings after reading the letter

- Evaluating the lessons learned and changes that occur during the process of the intervention program

\section{Procedure}

Procedure of the research was as follows: the licensing process, early assessment done through observation and interviews to DM 2 patients in Persadia, the making of "Pasien PANDAI" program module, role play module, module validation through expert

judgment, modification and validation of Adherence Scale to Medication and Acceptance and Action Scale, a test of the modules and depression scale, selection and orientation of facilitators and observers, the selection of research subjects, the implementation of "Pasien PANDAI" Program.

The implementation stages of the program were as follows: an initial meeting to obtain approval from the research of participants

(informed consent) to follow the whole process, the pre-test: participants fill-in the Adherence to Medication Scale and

Acceptance and Action Scale, implementation of the program: the meeting was done 5 times, for 3 weeks ( 2 hours each), post-test: participants fill-in the Adherence to Medication Scale and 
Journal of Educational, Health and Community Psychology

Acceptance and Action Scale on the final day of training, evaluation of the training and the manipulation check: giving feedbacks about the perceived change, the usefulness of the program sessions, program implementation, and facilitators' capacity in delivering materials and about the benefits of the program.

\section{Results}

The results of this study are divided into two parts, namely the quantitative data in the form of group data analysis and descriptive data (additional data) which is the result of the individual analysis. Description of the results of the analysis of each of the data is described as follows:

\section{Quantitative Analysis}

The data obtained in this study originated from four subjects as in the first meeting; one subject withdrew for health reasons. To determine the change in subject scores before and after the intervention, can be seen be seen in the table below:

Table 2

Descriptive Data level of Adherence to Medication

\begin{tabular}{lcc}
\hline Measurement & $M$ & $S D$ \\
\hline Pretest & 47,50 & 1,732 \\
Posttest & 55,75 & 6,652 \\
Follow-up & 56,25 & 5,620 \\
\hline
\end{tabular}

Based on the descriptive data in Table 2, it can be seen that there is an increase in the mean score of adherence to medication after receiving the intervention. The increase of mean score for adherence to medication is 8.25 points in posttest measurement and 8.75 points in the follow-up measurement. This descriptive data indicates that there is an increase in the mean scores between the adherence subject before and after receiving the intervention. Furthermore, to determine whether the increase in scores is statistically significant or not, researchers conducted a test towards the hypothesis of this study.

The Hypothesis Testing is done with the Wilcoxon Signed Rank test. Hypothesis test results of this study are as follows: 
Journal of Educational, Health and Community Psychology

Vol 5, No 2, 2016

Siti Muthia Dinni

Table 3

Hypothesis Testing Results (Wilcoxon Signed Rank Test)

\begin{tabular}{ccc}
\hline & Adherence Post-Pre & Adherence Follow Up-Post \\
\hline$Z$ & $-1,826$ & $-0,535$ \\
Asymp. Sig. (2-tailed) & 0,068 & 0,593 \\
\hline
\end{tabular}

The results of the study show that the "Pasien PANDAI" Program does not create a significant effect towards adherence to medication in DM 2 patients $(\mathrm{Z}=-1826, \mathrm{p}=$ $0,068)$. The result of analysis of differences in the posttest and follow-up scores also indicate that the level of adherence to medication tended to persist postintervention or do not show a significant difference $(\mathrm{Z}=-0.535, \mathrm{p}=0.593)$. Based on the analysis above, it can be concluded that the hypothesis is rejected. The "Pasien PANDAI" (Patients with Acceptance and Action) Program can not improve adherence to medication in patients with DM 2.

\section{Descriptive Analysis}

Descriptive analysis of the data is collected based on the change in the measurement of individual scores, interviews, observation, Diary, SmartBook, the results of the evaluation and manipulation check. Based on a thorough discussion of the development of the four subjects, it can be concluded that all subjects experienced an increase in score of adherence to medication. Three subjects also experienced an increase in the category, from of moderate to high. After attending the program, the subject finds it easier to accept themselves as a DM 2 patient, feel calmer, feel less rash, fresher, has it easier to concentrate, better at recognizing the value of life, motivated to maintain their health, and also feel more confident in doing selfmanagement. This shows that the purpose of the implementation of this module is achievable.

Things that support the success of each in the intervention was active participation of the subject, the subjects' success in putting meaning in each process of the program, subjects' willingness to implement learnt lessons into their daily life, the willingness to understand oneself, willingness subject to find new information in the discussion process, and the subjects' internal motivation to implement behavior change.

There is a tendency that the illness and amputation of a subject who had dropped out 
Journal of Educational, Health and Community Psychology

Vol 5, No 2, 2016

Siti Muthia Dinni

to cause distress that affects the level of acceptance of the four subjects.

\section{Discussion}

This research was aimed to verify whether or not the "Pasien PANDAI" Program (Patients with Acceptance and Action) can increase adherence to medication in DM 2 patients. The result of this research shows that the research hypothesis is rejected. The "Pasien PANDAI" Program was unable to increase adherence to medication in DM II patients ( $\mathrm{Z}$ $=-1,826 ; \mathrm{p}=0,068)$, where the result remained constant until the follow-up process $(\mathrm{Z}=-0,535, \mathrm{p}=0,593)$.

Prior researches showed that interventions based on aspects of acceptance, commitment formation, as well as behavioral change has proven to be effective to overcome various psychological problems in DM II patients, where subsequently their self-management also increased (Gregg, 2004; Forman, et al., 2009; Hartmann, et al., 2009). Therefore, the results obtained in this study are not consistent with previous studies.

One of the factors that contribute to the statistical insignificance of this research is the small number of subjects (4 people). Shadish, etc. (2002) said that a limited number of the subject could be the source of low statical power in quasi-experiment research. Parallel to the research of
McCracken, Sato, and Taylor (2013), implementation of Acceptance and Commitment Therapy (ACT) chronic pain patients showed small-medium effect size-due to a considerably small amount of subject.

In addition to the factor of the number of subjects, other factors that are thought to influence the results are the very tight schedule during program execution. Meetings I-III was held continuously without any alternating days off to adjust the schedules of those involved in the program, as well as considering the mortal risk. Ideally, a program that uses the concept of brief group ACT requires a resting period, in which patients interpret and apply what they have learned (McCracken, Sato, and Taylor, 2013).

The last contributing factors are the condition of the subject. The subject of this research are patients with DM 2 and is considered to be entering later years of life. During program execution, subjects appear to get tired easily, not allowing the presented material to be interpreted optimally. This condition also leads to errors in the measurement process that in turn affects the outcome.

Although statistical results of this research are insignificant, the result of the descriptive analysis shows that research subjects feel the 
Journal of Educational, Health and Community Psychology

benefit of participating in the program. The level of adherence to medication in subjects increases from the moderate category to higher category, where the result is found to be constant until following-up process. Subjects' adherence to medication increases due to the increase of self-acceptance, in which subjects can accept their illness, have a greater value of life, is more motivated to maintain their health, and is more confident in their self-management. Based on their evaluation results, subjects state that they are still conducting the things they have learned even after the program ended, and still feels the benefit of it. Goldstein (1981) states that the effectiveness of training is seen by how participants can implement what they learned in their everyday lives.

Subjects who experience significant increases in this research is characterized by their success in giving meaning towards every process in the program as well as being able to implement it in their everyday lives. This is based on their active participation, eagerness to understand themselves, as well as a strong internal commitment. Ramdhani (2002) states that active involvement and learning experience of subjects can be an asset that leads to optimal learning transfer, as they are not only taking a passive role.

The emerged inconsistency between the result of the statistical and descriptive analysis in this result indicates that the researcher ought to pay more attention to the clinical significance. Marczyk, DeMatteo, and Festinger (2005) states that the interpretation process of a research result should consider not only its statistical significance but also the value of $\mathrm{p}$. The researcher needs to examine various other indexes, such as effect size or subject percentage that will move from the "out-ofnormal range" to "normal range."

In this research, it is predicted that the amputation incident of one the group members who experienced mortal distressed the four subject. From the descriptive data, the rise and fall of subjects' checklist graphic are related to this incident. The adherence to medication graphic as well as subjects' acceptance tends to decrease if on same day subjects receive news or visit the mortal subject. That is possible because the existence of social comparison that is done by research subjects. According to the research results of Vander Zee, Buunk, Sanderman, Botke, and Bergh (2000), social comparison negatively correlates with the level of adaptation in the context of a selfhelp group for patients with chronic illness. The negative interpretation of the process of comparison is associated with the emergence of rejection (denial) in comparison to positive coping behavior.

Based on the results of evaluation, all subjects expressed that the session they felt 
Journal of Educational, Health and Community Psychology

is most beneficial is relaxation and Plan for Health Action (Rencana Aksi Sehat). For the relaxation, all subjects felt calm, relaxed, not hasty, light, fresh and have a higher concentration. Smeltzer and Bare (2002) states that deep-breath relaxation can enhance alveoli ventilation maintain gas exchange, prevents lung delectation, increase coughing efficiency, reduce the physical and emotional stress that reduces pain intensity and anxiety.

About the Plan of Health Action (Rencana Aksi Sehat), subjects express that this session helps them realize that "commitment" is crucial in habituating a healthy life-style, making them more motivated to maintain their health, as well as confidence in self-management. The Plan for Health Action (Rencana Aksi Sehat) action and its implementation is founded based on behavioral intervention that aims to encourage subjects to make behavioral plans and implement them in a period of 1 week. A research result from Widyaningrum (2014) shows that the intervention based on behavioral approach such as Behavioural
Activation is proven to be effective in increasing self-management in DM 2 patients.

Based on the elaboration of research analysis above, it can be concluded that the "Pasien PANDAI" Program cannot increase adherence to medication in DM 2 patients, starting from posttest to follow-up. However, from the descriptive analysis, it can be seen that patients still feel the benefits of this program, finds it easier to accept themselves as a DM 2 patient, feel calmer, feel less rash, fresher, has it easier to concentrate, better at recognizing the value of life, motivated to maintain their health, and also feel more confident in doing self-management. The result of this research shows that the "Pasien PANDAI" Program can be an alternative psychological intervention for DM 2 patients. Future researchers are suggested to use an experimental design with a control group, add subjects, and have resting days after each session, and implement this module for different lines or different age group.

\section{References}

Basyiroh, A. N. (2011). Hubungan antara kontrol diri dengan kepatuhan terhadap pengobatan pada pasien diabetes mellitus tipe 2 di RSUD DR. Moewardi Sarakarta. Skripsi Tidsak diterbitkan. Universitas Muhammadiyah Surakarta. Surakarta. 
Journal of Educational, Health and Community Psychology

Vol 5, No 2, 2016

Siti Muthia Dinni

Bautista, L. E., Vera-Cala, 1. M., Colombo, C., \& Smith, P. (2012). Symptoms of depression and anxiety and adherence to antihypertensive medication. American Journal of Hypertension, 25 (4), 505-611.

Bond, F. W., Hayes., S. C., Baer, R. A., Carpenter, K. M., Guenole, N., Orcutt, H. K., ... Zettle, R. D. (2011). Preliminary Psychometric Properties of the Acceptance and Action Questionnaire-2: A Revised Measure of Psychological Inflexibility and Experiential Avoidance. Behavior Therapy, 42, 676-688.

Ciechanowski, P., Wayne, K., Joan E., R., \& Edward A., W. (2001). The patient-provider relationship: attachment theory and adherence to treatment in diabetes. The American Journal of Psychiatry, 158 (1), 29-35.

Delamater, A. M. (2006). Improving patience adherence. Clinical Diabetes Journals, 24 (2), 7177.

Devaramane, V., Pai, N. B., \& Vella, S-L. (2011). The Effect of Brief Family Intervention on Primary Carer's Functioning and Their Schizophrenia Relatives Level of Psychopathology in India. Asian Journal of Psychiatry, 2, 210-222.

Dinkes DIY. (2013). Profil kesehatan Daerah Istimewa Yogyakarta tahun 2013. Dinkes DIY : Yogyakarta.

Formann, E. M., Butryn, M. L., Hoffman, K. L., \& Herbert, J. D. (2009). An open trial of an acceptance-based behavioral intervention for weight loss. Cognitive and Behavioral Practice, 16 (2), 223-235.

Gray, W. N. Denson, L. A., Baldassano, R. N., \& Hommel, K. A. (2011). Treatment adherence in adolescents with inflammatory bowel disease: the collective impact of barriers to adherence and anxiety /depressive symptoms. Journal Pediatry Psychology, 37(3), 282-291.

Gregg, J. A. (2004). A randomized controlled effectiveness trial comparing patient education with and without Acceptance and Commitment Therapy for type 2 diabetes self- 
Journal of Educational, Health and Community Psychology

Vol 5, No 2, 2016

Siti Muthia Dinni

management. Dissertation of University of Nevada. Nevada: University of Nevada.

Hartmann, M., Kopf, S., Kircher, C., Faude-Lang, V., Djuric, Z., Augstein, F., ... Nawroth, P. P. (2012). Sustained effect of a mindfulness-based stress-reduction intervention in type 2 diabetic patients. Diabetes Care, 35, 945-947.

Hasanat, N.U. (2008). Aspek psikologik pada penyandang diabetes dan keluarga penyandang diabetes diabetes melitus dalam manajemen diabetes melitus: Studi Eksplorasi. Laporan Penelitian (unpublished). Yogyakarta: Fakultas Psikologi Universitas Gadjah Mada .

Hayes, S., \& Strosahl, K. (2004). A practical guide to acceptance and commitment therapy. New York: Springer.

Haynes R. B, McDonald H. P, \& Garg A. X. (2002). Helping patients follow prescribed treatments. Journal of American Medicine, 288, 2880-2883.

Hjelle, L. A., \& Zeigler, D. J. (1992). Personality theories: Basic assumption, research, and application. Tokyo: Mc Graw Hill, Inc.

Kementrian Kesehatan RI. (2013). Riset kesehatan dasar (RISKESDAS) 2013. Jakarta: Badan Penelitian 7 Pengembangan Kesehatan Kementrian RI.

McCracken, L. M. \& Vowls, K. E. (2006). Acceptance of the pain. Current Pain and Headache Reports, 10, 90-94.

Misra, R. \& Lager, J. (2008). Predictors of quality of life among adults with type 2 diabetes Mellitus. Journal of Diabetes and Its Complication, 22, 217-223.

Razali, R. M., Bee, P. C., \& Gan, G. G. (2013). Surveys of Willingness to Accept Chemotherapy among Elderly Malaysian Patients. Asian Pacific Journal of Cancer Prevention, 4, 2029-2032.

Ridder, D., Geenen, R., Kujer, R., \& Middendorp, H. (2008). Psychological adjustment to chronic 
Journal of Educational, Health and Community Psychology

Vol 5, No 2, 2016

Siti Muthia Dinni

disease. Lancet, 372, 246-255.

Seligman, M. E. (1991). Learned optimism. New York: Alferd A Knopf Inc.

Shadish, W., Cook, T., \& Campbell, D. (2002). Experimental and quasi-experimental designs for generalized causal inference. Boston: Houghton Mifflin Company.

Taylor, S. E. (2006). Health psychology 6th edition. New York: McGraw-Hill Inc.

Werch, C. C., Grenard, J. L., Burnet, J., Watkins, J. A., Watkins, J. A., \& Ames, S. (2006). Translation as a function of modality the potential of brief intervention. Evaluation \& The Health Profession, 29 (1), 89-125.

World Health Organization (WHO). (2013). Diabetes. Go online to: http://who.int.

World Health Organization (WHO). (2012). WHOQOL user manual. Geneva: WHO.

Yalom, I. D., \& Leszcz, M. (2005). The theory and practice of group psychotherapy: The fifth edition. New York: Basic Books. 